\title{
NARRATIVAS DE VIAJANTES DE CIÊNCIA PELA AMAZÔNIA: IMPORTA QUEM FALA?
}

\section{SCIENCE TRAVELER NARRATIVES: DOES IT MATTER WHO SPEAKS?}

\author{
Raquel Alves Ishii ${ }^{1}$, Juciane dos Santos Cavalheiro ${ }^{2}$
}

\begin{abstract}
RESUMO: Este artigo visa analisar narrativas de viajantes de ciência pela Amazônia do século XIX a partir das questões sobre autoria desenvolvidas por Michel Foucault. Dividido em duas partes, busca-se primeiro apresentar o pensamento de Foucault, cuja análise de textos pretende ir além do recorte de autor e obra. Em seguida, apresenta-se uma breve discussão historiográfica das narrativas de viajantes de ciência enfatizando não a autoria, mas a "função autor" que age como instância discursiva ou instrumento de regramentos de discursividade sobre o quê e o como pode ser dito. Do mesmo modo, em se tratando de discursos de ciência, os elementos da técnica, especialmente a catalogação de espécimes da fauna e flora amazônica, bem como o papel das instituições de pesquisa na produção e circulação de relatos de viajantes de ciência são apresentados como princípios norteadores de uma análise dos mecanismos que produzem e legitimam um discurso de autoridade.
\end{abstract}

PALAVRAS-CHAVE: Função autor; narrativas de ciência; relatos de viagem; Amazônia

\begin{abstract}
This article aims to analyse 19th century narratives of Amazon science travelers considering the discussion on authorship developed by Michel Foucault. Divided into two parts, we first seek to present Foucault's thought, whose text analysis intends to go beyond of author and work as a methodological standpoint. In a second step, a brief discussion about historiographic paths of science travelers' narrative publications is presented, emphasizing not authorship, but the "author function" that acts as a discursive instance or instrument of discourse rules about what and how it can be spoken. Likewise, in the case of science discourses, the elements of the technique, especially the cataloging of specimens of Amazonian fauna and flora, as well as the role of research institutions in the production and circulation of science traveler reports are presented as guiding principles on the analysis of the mechanisms that produce and legitimize a discourse of authority.
\end{abstract}

KEYWORDS: Author function; Science narratives; Travel Reports; Amazon

\section{Introdução}

\footnotetext{
${ }^{1}$ Doutoranda pelo PPG em Letras: Linguagem e Identidade da UFAC.

${ }^{2}$ Doutora em Linguística pela UFPB. Professora da UEA e docente no PPG em Letras e Artes da UEA e no PPG em Letras UFAC.
} 
Neste artigo, pretende-se abordar a função autor - entendida nos termos de Michel Foucault - a partir de relatos de "viajantes de ciência" que tematizaram a região Amazônica, produzidos durante a segunda metade do século XIX. Marcados ao mesmo tempo pela autoridade da técnica e por sua vinculação institucional, os relatos foram escritos por viajantes de distintas localidades do continente europeu que, em grande parte, possuíam sólida formação humanística, ora a serviço de instituições de pesquisa, ora comissionados por agentes oficiais, ora decididos a aventurar-se às suas próprias expensas. Tais viajantes "estrangeiros", no percurso de sua vivência em terras brasileiras, compuseram um acervo que nos permite, na atualidade, revisitar a indagação a que Foucault se propõe, lendo Samuel Beckett: "importa quem fala?" Para tanto, busca-se neste artigo definir e analisar, em um primeiro momento, o sentido da função autor, e, posteriormente, compreender como tal função permite pensar a produção escrita de viajantes, seus discursos, para além dos recortes de autor e obra.

\section{Sobre o autor: a obra e a escrita da obra}

Na comunicação intitulada $O$ que é um autor? proferida, no ano de 1969, à Sociedade Francesa de Filosofia, Michel Foucault elabora uma análise que confronta a crítica literária e a filosofia moderna, por sua modalidade de apreciação quase religiosa - para não dizer idealista, de modo que questões envolvendo a relação entre autor e obra literária lhe são, por vezes, indiferentes. Também, faz autocrítica e responde a objeções feitas à publicação de As palavras e as coisas (1966), ao eleger a questão da obra e da escrita como ponto de partida para sua reflexão a respeito da autoria, cuja má compreensão leva à não percepção da verificação da inexistência do autor, enquanto sujeito produtor de textos, e à sua, por assim dizer, "existência", enquanto instância discursiva, recurso ou instrumento de regramentos de discursividade.

De início, uma reflexão sobre o papel social da escrita possibilita entender o cenário em que o tema se dá. A escrita, segundo Foucault (2009), libertou-se do "tema da expressão" e se lhe atribuiu sentido em si, sem deixar de identificar-se com sua exterioridade, atuando como em um jogo em que o sujeito que escreve destina-se ao desaparecimento. A escrita não mais conjura a morte como na antiguidade europeia e ocidental ${ }^{3}$, mas é agora seu sacrifício e relaciona-se com o apagamento da individualidade dos sujeitos ou, em outras palavras, com a morte do autor:

\footnotetext{
${ }^{3}$ Embora não seja o foco deste artigo, depois de O encobrimento do outro, de Enrique Dussel, não nos permitimos o uso impune de termos como "europeu" e "ocidental", pois como todo conceito, estes não existem em si, e necessitam ser interrogados em sua pretensiosa essência. 
Não se trata de afirmar que o homem está morto (ou que vai desaparecer, ou que será substituído pelo super-homem), trata-se, a partir desse tema, que não é meu e que não cessou de ser repetido desde o final do século XIX, de ver de que maneira e segundo que regras se formou e funcionou o conceito de homem. Fiz a mesma coisa para a noção de autor. Contenhamos, pois, as lágrimas. (FOUCAULT, 2009, p. 81).

Os temas da morte do homem, de deus e do autor que perpassam os estudos no campo da filosofia, da literatura e da linguagem em geral se traduzem ainda pela compreensão de sua existência transcendental. Esta constatação não implica dizer, no entanto, que tais conceitos não operem discursivamente, ou seja, que não possuam uma função ou que não sejam parte do jogo que estabelece o que pode ou não ser dito, quem pode ou não dizer. Nesse caso, se o autor está morto, a função autor nunca esteve tão viva.

Assim, dentre as várias noções que são problematizadas por Foucault, questionando óbvios não tão óbvios, duas delas, particularmente, articulam as demais. A primeira se formula por meio da pergunta: o que é uma obra? Ele próprio irá nos apontar sua problemática definição conceitual muito utilizada como paradigma em análises de crítica literária. Análises essas em que não se tem buscado

detectar as relações da obra com o autor, nem reconstituir através dos textos um pensamento ou uma experiência (...) [mas] sim, analisar a obra na sua estrutura, na sua arquitectura, na sua forma intrínseca e no jogo das suas relações internas. Ora, é preciso levantar de imediato um problema: “O que é uma obra?” (FOUCAULT, 2009, p. 37).

A esse paradigma de análise, Foucault argumenta: de que falamos quando falamos, por exemplo, da obra de F. Nietzsche?

Tudo que Nietzsche publicou, sem dúvida. Os rascunhos de suas obras? Evidentemente. (...) Mas, quando no interior de um caderno cheio de aforismo, se encontra uma referência, uma indicação de um encontro ou um endereço, um recibo de lavanderia: obra ou não? Mas por que não? (p. 38).

“A teoria da obra não existe", assevera Foucault. "De tal forma que não basta afirmar: deixemos o escritor, deixemos o autor, e estudemos a obra em si mesma. A palavra 'obra' e a unidade que ela designa são provavelmente tão problemáticas como a individualidade do autor" (FOUCAULT, 2009, p. 39). Assim, a questão da autoria assume contornos bem mais difusos quando não há, de igual modo, clareza sobre o que venha a ser tal entidade.

A segunda noção, já comentada, é a noção de escrita que "com sutileza”, dirá Foucault, preserva a existência de um autor metafísico, ao passo em que apaga suas singularidades, privilegiando o estudo da "condição do espaço onde se dispersa e do tempo em que se desenrola" (2009, p. 39). A noção de escrita corrente produz um "anonimato transcendental" do autor, neutralizando-o e situando-o no lugar privilegiado do "a priori": o autor antecede a existência da obra. A escrita é entendida, portanto, como ausência, ao passo que a ela se atribui 
um sentido idealista e originário. Ausente de sujeito, a escrita põe em ação a modalidade crítica e a modalidade religiosa de abordagem de textos que se equivalem em termos teóricometodológicos, uma vez que partilham de princípios como o sentido oculto, os implícitos, as determinações silenciosas e conteúdos obscuros no texto, dando passagem para a necessidade de interpretar e comentar.

O desaparecimento do autor, desse modo, como tem sido anunciado, encontra-se ainda em uma clausura transcendental. Foucault se propõe então a "localizar o espaço deixado vazio pelo desaparecimento do autor, seguir de perto a repartição das lacunas e das fissuras e perscrutar os espaços, as funções livres que esse desaparecimento deixa a descoberto." (2009, p. 41) e passa, a partir de então, a explicitar sua tese sobre a autoria e sua função discursiva. Enquanto o autor assume, outrossim, um caráter de um ente metafísico e o entrelaçamento que se dá entre sua biografia e sua obra se caracteriza pela constituição de um sujeito moderno e ocidental, a função autor é apontada como sendo "característica do modo de existência, de circulação e de funcionamento de alguns discursos no interior de uma sociedade" (2009, p. 46), constituído de um estatuto fundacional no interior de discursos, instaurando discursividade.

Assim como a assinatura para J. Derrida (1995) não é um nome próprio, mas uma instância discursiva, o nome do autor para Foucault não se refere a um sujeito específico, mas a uma função que atua como um instrumento de classificação, de (re)agrupamento de textos, delimitando-os, selecionando-os, opondo-os uns aos outros, caracterizando um certo modo de ser no discurso, cuja recepção deve ser específica e receber certo estatuto a depender da sociedade em que se insere.

\footnotetext{
A função autor está ligada ao sistema jurídico e institucional que encerra, determina, articula o universo dos discursos; não se exerce uniformemente e da mesma maneira sobre todos os discursos, em todas as épocas e em todas as formas de civilização; não se define pela atribuição espontânea de um discurso ao seu produtor, mas através de uma série de operações específicas e complexas; não reenvia pura e simplesmente para um indivíduo real, podendo dar lugar a vários "eus" em, simultâneo, a várias posições-sujeitos que classes diferentes e indivíduos podem ocupar. (FOUCAULT, 2009, p. 56-57).
}

Em síntese, a função autor caracteriza-se pela sua vinculação a um sistema jurídico e institucional, por constituir-se de um estatuto de autoridade, por seu valor estilístico e por sua a posição transdiscursiva ou pluralidade de "eus".

\section{Narrativas de ciência: autoridade da escrita e vinculação institucional}


As narrativas de que tratam este artigo são comumente classificadas como narrativas "de ciência", produzidas em grande escala durante o século XIX, um período do "boom" científico europeu. Recebem, segundo Foucault, tratamento diferenciado quanto à autoria:

(...) se na matemática a referência ao autor pouco mais é do que uma maneira de nomear os teoremas ou conjuntos de proposições, em biologia e em medicina a indicação do autor e da data do trabalho têm um papel bastante diferente: não se trata simplesmente de indicar a fonte, mas de dar algum indício de "fiabilidade" relativamente às técnicas e aos objetos de experimentação utilizados num dado momento e num determinado laboratório. (FOUCAULT, 2009, p. 50).

E como narrativas que carecem de inserção em uma determinada formação discursiva, não é aleatória a forma como se decide escrever, ou melhor, descrever, relatar a verdade, o que é. A escolha pelo relato de ciência - e também de viagem - é, dessa forma, um modo institucionalmente aceito e autorizado de se fazer ciência e, consequentemente, de possibilitar a sua circulação e legitimação institucional.

Seguindo os passos de M. Foucault, o objetivo não é elaborar uma fiel descrição do perfil sobre o que venha a ser um viajante pela Amazônia do século XIX, ou um estudo de sua obra, mas antes de tudo, percorrer os caminhos que traçaram as regras e as historicidades que permitiram que (re)produzissem tais discursos e não outros.

Em se tratando de textos de viajantes, em grande parte naturalistas, pode-se dizer que a função autor concorre para sua neutralização, necessitando fazer desaparecer suas marcas de subjetividade - um projeto sempre ilusório - de uma escrita que se apresenta como a descrição fiel do real, autocomprovada, não pela sua autoria, contudo por atuar como se um instrumento técnico fosse e que permitiria ao leitor a própria experiência do contato com realidades diferentes da sua. Narrar, contar, descrever, referir, mencionar constituem-se como uma prática discursiva cuja escrita é prenhe de autoridade ou "fiabilidade" sobre o que é narrado.

A mudança de compreensão da noção de escrita e de desaparecimento do autor assumindo funções distintas no que se refere a áreas de conhecimento é também analisada por Foucault. A autoria como indício de veracidade cede lugar a um conjunto de procedimentos que compõe uma escrita que ser pretende demonstrável e anônima. Em suas palavras:

Os textos que hoje chamaríamos científicos, versando a cosmologia e o céu, a medicina e as doenças, as ciências naturais ou a geografia, eram recebidos na Idade Média como portadores do valor de verdade apenas na condição de serem assinalados com o nome do autor. "Hipócrates disse", "Plínio conta" não eram, em rigor, fórmulas de um argumento de autoridade; eram indícios que assinalavam os discursos destinados a ser recebidos como provados. (FOUCAULT, 2009, p. 48-49).

E continua: 
No século XVII ou no XVIII produziu-se um quiasma; começou-se a receber os discursos científicos por si mesmos, no anonimato de uma verdade estabelecida ou constantemente demonstrável; é a sua pertença a um conjunto sistemático que lhes confere garantias e não a referência ao indivíduo que os produziu. (FOUCAULT, 2009, p. 49).

Reside, logo, nessa prática discursiva, a indiferença traduzida pela indagação: "Importa quem fala?" Não obstante o (re)conhecimento relativo - e sempre a posteriori - que se dê a Alfred Wallace, Henry Bates, James Wells, Robert Avé-Lallemant, Charles La Condamine, Spix e Martius, William Chandless, ao casal Agassiz e a tantos outros médicos, botânicos, geógrafos, engenheiros e naturalistas de toda sorte que singraram rios e florestas amazônicas, registrando, dando a ver, a conhecer, nomeando e conferindo existência, ao narrar, localidades e pessoas, suas escritas não remetem ao indivíduo que as escreve. Embora se relate em primeira pessoa, antes de expressar singularidades ou seu estilo, a escrita de viajantes de ciência ganha contornos de testemunho ocular, em uma narrativa autocomprovada por meio do uso de instrumentos técnicos, imagens, mapas e sistemas de classificação da natureza, além de estar mediada por sua vinculação a instituições de pesquisa, universidades, museus, associações científicas, editoras e governos.

Quando William Chandless publicou A visit to Salt Lake: being a journey across the plains, and a residence in the Mormon settlements at Utah, no ano de 1857, sua escrita era marcada muito mais por suas impressões de viajante, em um ritmo de diário pessoal do que pela objetividade que predomina em seus relatos sobre rios amazônicos. Ainda assim, já demonstrava preocupação em não escrever "ficção", compreendida como não-verdade, e em demonstrar autenticidade sobre o relatado: "nenhum incidente foi introduzido para fundamentar qualquer opinião, ou como forma de ilustrar costumes e sentimentos, ou mesmo para qualquer outra finalidade, a menos que tenha ocorrido." (CHANDLESS, 1857, p. V). A experiência, como prática sensorial e modo de apreensão do real em detrimento da imaginação ou da criação ficcional já despontava sua escrita, impregnada de uma lógica racionalista de apreensão do mundo natural.

Seus relatos de viagem sobre rios, constituem-se, por outro lado, em relatos de ciência e, portanto, sua narrativa assume um caráter impessoal e direto, consolidando uma separação entre aquele que escreve e o que se escreve. Em suas palavras, quando de sua viagem ao Rio Purus: "há pouco interesse e importância em relatar detalhes pessoais em uma expedição sobre o rio Purus. Por isso mesmo, os omiti." (CHANDLESS, 1866, p. 92). Ao mesmo tempo, os dados sobre coordenadas geográficas, temperatura dos rios, densidade demográfica, distância entre cidades e vilas, preços e quantidades de produtos naturais como cacau, salsaparrilha, café, 
tabaco, copaíba e borracha, sem contar a produção de mapas da região dos rios explorados com coordenadas geográficas, precisão de detalhes e com uma consequente identificação de localidades com "potencial econômico", pululam a todo momento da narrativa conferindo autoridade técnica para sua própria existência e veiculação. Mesmo a descrição de sujeitos e práticas culturais são igualmente objetificadas pela escrita tecnicamente instrumentalizada, nivelando em um mesmo plano homem e natureza.

Sobre este aspecto, há que se ressaltar que a dimensão antropocêntrica que atravessa os relatos de viajantes ingleses no Brasil, em especial os produzidos no final do século XVIII e durante todo o XIX, trata a relação homem-natureza como instâncias autônomas baseada na premissa da dominação do primeiro sobre o segundo, e que termina, também, por estabelecer relações de superioridade e subalternidade entre os próprios homens, ao produzir uma subrelação traduzida no par civilizado-primitivo. Os indivíduos primitivos estariam então no nível da natureza e careceriam de domesticação do mesmo modo que as terras de cultivo (THOMAS, 1988).

Esses dois movimentos de escrita do viajante William Chandless possuem repercussões distintas. A publicação de A visit to Salt Lake... feita pela Smith, Elder Publishers, mesma Editora que publicou todos os volumes de Zoology of the Voyage of the Beagle de Charles Darwin, durante a década de 1840, permitiu uma circulação entre um público amplo e não especializado, rendendo-lhe além da tradução para o alemão, várias outras edições em língua inglesa por outras editoras (ISHII, 2019, p. 44). Seus relatos sobre rios, no entanto, mantiveramse restritos a um circuito seleto, reconhecidos por também viajantes e exploradores, mas foram especialmente classificados em uma outra tipologia de relatos, devido aos interesses institucionais que permearam sua produção e circulação: a publicação foi feita, no Brasil, pelo Ministério da Agricultura, em relatórios de presidentes da então província do Amazonas, e na Inglaterra, pela Royal Geographical Society, que acumula, na atualidade, quase duzentos anos de relatos e narrativas reportadas por viajantes que cruzaram os cinco continentes.

O papel de instituições na produção e circulação de discursos de ciência, a exemplo das sociedades de geografia, é tema bastante conhecido. Um interessante estudo sobre o discurso racial no Brasil é feito por Lilia Schwarcz em O espetáculo das raças: cientistas, instituições e questão racial no Brasil - 1870-1930 (1993). Schwarcz (1993) mostra como museus etnográficos, institutos históricos e geográficos, faculdades de direito e de medicina possuíam importante função legitimadora de teses raciais. E é esta relação entre instituições científicas e o ordenamento discursivo que rege tais aparatos que termina por legitimar as narrativas de sujeitos inominados pondo em funcionamento a função autor. O discurso científico, em 
particular o discurso em torno das Ciências Naturais, como alerta Foucault, é dado não apenas pela escrita anônima e objetivista, mas por seu acolhimento em um ordenamento jurídico de uma entidade que atua em sua difusão. Os discursos científicos requerem que seus círculos restritos se legitimem mutuamente, premiando-se e referenciando-se como forma de conferir fiabilidade ao que é dito. No dizer de Mary Pratt:

[o]s relatos jornalísticos e a narrativa de viagem, contudo, eram mediadores essenciais entre a rede científica e o público europeu mais amplo, pois eram agentes centrais na legitimação da autoridade científica e de seu projeto global, ao lado de outras formas europeias de ver o mundo e habitá-lo. (1999, p. 63).

Os ingleses Alfred Wallace e Henry Bates, quando de sua passagem pelos rios amazônicos, catalogaram um numeroso volume de espécies de animais e plantas dessas localidades. Tanto em The naturalist on the River Amazons (1910) quanto em A narrative of travels on the Amazon and Rio Negro (1889), a escrita pitoresca, as gravuras ou estampas de objetos, plantas e animais, paisagens e pessoas, conduzem o olhar a uma percepção do real em que o relato de ciência é tornado a coisa em si, comprovado pelo uso do barômetro, da bússola e pela mão que registra imagens de palavras e imagens em desenhos.

Wallace e Bates, também, mantinham relações com a Royal Geographical Society. Segundo Ricardo Ferreira, além de terem seus escritos publicados em revistas e atas da sociedade, ambos concorreram, recomendados por Charles Darwin, ao cargo de secretário assistente da sociedade. Na época,

(...) a Royal Geographical Society ainda estava envolvida nas explorações de regiões desconhecidas do globo, notadamente na África, embora a febre exploratória tivesse passado, dando lugar à investigação geográfica com finalidades científicas. (FERREIRA, 1990, p. 78).

Essa mesma instituição, nunca é demais lembrar, abrigou como fellows membros cientistas responsáveis pelo contrabando de sementes de Hevea brasiliensis e de cinchona, de onde desenvolveram a extração da quinina (FERREIRA, 1990, p. 78-79). Desde a sua fundação, em 1830, a sociedade tem reunido e publicado, promovido e classificado, difundido e preservado, um volumoso acervo não apenas relacionados às Ciências Naturais, mas de valor histórico, etnográfico, linguístico, literário, econômico etc., possibilitando a circulação, valorização e apropriação de discursos porta-vozes da ciência ou de um estatuto de verdade.

Muitas outras instituições londrinas oitocentistas como a Sociedade Linneriana, Sociedade de Zoologia e Sociedade de Entomologia cumpriam o papel de não apenas difundir, mas regular a veiculação dos discursos científicos da época. Segundo o editor de A narrative of travels on the Amazon and Rio Negro..., George Thomas Bettany, ao longo de suas viagens 
científicas, Alfred Russel Wallace havia contribuído à época com 18 artigos científicos publicados por essas entidades, e com 12 outros para diversos periódicos voltados para às Ciências Naturais (1889, p. v). Amplamente nominado como co-descobridor do princípio da seleção natural, Alfred Wallace correspondeu-se com Charles Darwin antes e após a On the Origin of Species by Means of Natural Selection, or the Preservation of Favoured Races in the Struggle for Life, em 1859, sobre suas observações comparativas de espécies e de seus ancestrais comuns, estabelecendo uma relação de reciprocidade no âmbito das pesquisas que empreendiam a distância um do outro. A humildade de Wallace quanto à sua contribuição às Ciências Naturais era ressaltada pelo próprio Darwin: "Você é o único homem que conheço que, de modo insistente, comete injustiça contra si mesmo. Mas você não pode se silenciar, por mais que tente" (BETTANY, 1889, ix). A referência a Darwin, à época já amplamente reconhecida no meio científico, relaciona-se intimamente com a função autor como mecanismo que, assim como uma sociedade científica, instaura discursividade, ao não mais remeter ao sujeito sim, o autor de On the Origin of Species..., mas à função autor, posicionando a seu lado A. Wallace, cuja narrativa já se apresenta como autocomprovada.

Assim como tantos outros naturalistas, em sua viagem ao Brasil, Wallace dispôs de vários sistemas de classificação de animais e plantas como forma de descrever seu contato com realidades desconhecidas, à exemplo do Systema Naturae desenvolvido por Carl Linné durante o século XVIII, que, segundo Mary Pratt (1999), constituiu-se em um modelo de imposição da ordem ao caos da natureza, capaz de sistematizar, por exemplo, as plantas conhecidas e desconhecidas do público europeu. O emprego da técnica da classificação, desempenhada por meio de adoção de sistemas previamente estabelecidos, é utilizado por Wallace em diversas passagens de sua narrativa:

Muitas das maiores árvores florestais têm folhas tão delicadas quanto as da trêmula Mimosa, pertencendo como elas à extensa família das Leguminosae, enquanto as enormes folhas palmadas das Cecropias, as folhas brilhantes ovais das Clusias e centenas de outras de formas intermediárias, proporcionam variedade suficiente. (WALLACE, 1889, p. 18).

Além da inserção nos meios institucionais que envolviam o debate em torno das Ciências Naturais, bem como o reconhecimento público de Charles Darwin, o uso da técnica classificatória dos elementos da natureza (Mimosa, Leguminosae, Cecropias, Clusias), já amplamente reconhecidos pela comunidade científica, colaboram para que a narrativa de Wallace se constitua de autoridade científica, permitindo ou autorizando sua circulação nos meios acadêmicos da época. 
Editor da revista Transactions of the Royal Geographical Society por muitos anos, Henry Bates publicou a primeira edição de The Naturalist on the River Amazons... no ano de 1863. As dezenas de reedições que se seguiram contaram com o prestígio institucional que $H$. Bates possuía entre os membros da sociedade geográfica e, também, por atuar como secretário da entidade. A edição de 1910, publicada por J. M. Dent \& Sons e E. P. Dutton \& CO teve como seu prefaciador ninguém menos que Charles Darwin.

Darwin chama atenção para o fato de que H. Bates coletou cerca de 14.712 espécies de insetos durante seus onze anos de residência no Brasil, dos quais 8.000 eram completamente desconhecidas pelo público inglês. O longo tempo dedicado à pesquisa, os procedimentos de coleta e catalogação sistemática da volumosa coleção, além do próprio relato de viagem de Bates, assinalaram sua entrada definitiva nos círculos científicos londrinos como um respeitado entomologista. Darwin fez questão de enfatizar as descobertas de Bates sobre suas conclusões no campo do debate envolvendo a origem das espécies como forma de alinhá-lo a um discurso que ele próprio defendia: "Não precisamos dizer que o Sr. Bates, após a atenção que deu a essa questão, é um defensor esmerado da hipótese da origem das espécies por derivação de uma linhagem comum" (DARWIN, 1910. p. xi).

A autoridade da escrita de Henry Bates é, ainda, legitimada por Charles Darwin que atua não como um sujeito ou um autor que corrobora as reflexões de outro autor, mas como uma instância discursiva que representa sua autoridade institucional, ao mesmo tempo que Darwin reconhece nos relatos de Bates elementos que sustentam seu próprio discurso sobre a origem das espécies. Mais do que a referência formal entre estudos que se pautam pela conduta ética, há um processo de legitimidade recíproca entre discursos de ciência e que operam por diferentes procedimentos para constituir a autoridade que necessitam.

De forma mais sistemática do que Wallace, Henry Bates utiliza amplamente sistemas de classificação de plantas e animais, construindo uma narrativa marcada pela técnica científica e pela objetividade que pressupõe um discurso de autoridade:

Darei uma idéia da diversidade de borboletas. Lembrando que encontrei cerca de 700 espécies dessa ordem a uma hora da cidade, e que o número total de espécies encontradas nas Ilhas Britânicas não passa de 56, e toda a Europa possue apenas 321.Algumas das espécies mais vistosas tais como Papilio thoas, P. torquiatus, $P$. polycaon e outras, aparecem esvoaçando pelas ruas e jardins, e às vezes entram pelas janelas abertas, atraídas pelas flores de dentro de casa. As espécies de Papilio mais características da região, tão conspícuas em seus tons negro-veludoso, verde e roseo, e que Linneu, obedecendo ao seu elegante sistema de nomenclatura (designando as diferentes espécies em honra aos heróis da mitologia) chamou trojanus, nunca deixam as sombras da mata. (BATES, 1944, 136-137). 
A identificação de espécies de borboletas a partir do aludido sistema linneriano de classificação de animais, tais como a Papilio thoas, $P$. torquiatus e $P$. polycaon nos remetem, assim como o uso de mapas, barômetros, coordenadas geográficas, etc., ao saber relacionado ao conhecimento técnico que busca se estabelecer como um conhecimento verdadeiro, ainda hoje reconhecido e difundido - em que pese se encontre nessas mesmas narrativas, impressões que relativizam a escravidão negra e indígena e defendam a existência de uma relação hierárquica entre as civilizações.

Retomamos, pois, à indagação a que se submete Foucault: importa quem fala? A indiferença em relação à autoria nos remeteu à ausência do sujeito da linguagem, justamente pela não compreensão da existência da função autor. Como pensar, então, os relatos de ciência, que também são de viagem, a partir de outros paradigmas que não simplesmente os elementos internos de sua estrutura? E como analisar relatos de ciência a partir do autor e sua biografia, a obra e suas condições de produção, dado que autor e obra se encontram como elementos apriorísticos e transcendentais? Para Foucault, repensar os conceitos de autor e obra, corolários da metafísica, e a partir da função autor estudar as modalidades de existência dos discursos, entendendo que seus modos de circulação, de valorização, de atribuição e de apropriação variam com cada cultura, requerem ir além dos caracteres gramaticais e de suas estruturas formais, o que, por sua vez, permitiria a construção de uma tipologia dos discursos.

No caso específico de narrativas de ciência engendradas por meio de relatos de viagem, na esteira do debate sobre a função autor, a dimensão da técnica e do papel institucional de sociedades científicas, universidades e governos, constituem-se como princípios para a construção da tipologia discursiva a que nos remete Foucault, permitindo melhor compreender que importa pensar não apenas quem fala, mas como e através de que meios fala.

\section{REFERÊNCIAS}

BATES, Henry Walter. Um naturalista no rio Amazonas. Trad., prefácio e notas Candido Mello-Leitão. Vol. 1. São Paulo; Rio de Janeiro; Bahia; Recife; Porto Alegre: Companhia Editora Nacional São Paulo, 1944. Disponível em: https://bit.ly/2ZZQnYI. Acesso em: 20 mai. de 2020.

BATES, Henry Walter. The Naturalist on the River Amazons: a Record of the Adventures, Habits of Animals, Sketches of Brazilian and Indian Life, and Aspects of Nature under the Equator, during Eleven Years of Travel. London, Toronto: J. M. Dent \& Sons. New York: E. P. Dutton \& CO, 1910. Disponível em: https://bit.ly/3eylA9A. Acesso em: 28 mai. de 2020. DARWIN, Charles. An appreciation. Prefácio. In: BATES, Henry Walter. The Naturalist on the River Amazons: a Record of the Adventures, Habits of Animals, Sketches of Brazilian and Indian Life, and Aspects of Nature under the Equator, during Eleven Years of Travel. 
London, Toronto: J. M. Dent \& Sons. New York: E. P. Dutton \& CO, 1910. Disponível em: https://bit.ly/3eylA9A. Acesso em: 28 mai. de 2020.

BETTANY, George Thomas. Biographical Introduction. In: WALLACE, Alfred Russel. A narrative of travels on the Amazon and Rio Negro: with an account of the native tribes, and observations of the climate, geology, and natural history of the Amazon Valley. London; New York; Melbourne: Ward, Lock \& CO,1889. Disponível em: https://bit.ly/2U0pLD0. Acesso em: 28 mai. de 2020.

CHANDLESS, William. A visit to Salt Lake: being a journey across the plains, and a residence in the Mormon settlements at Utah. London: Smith, Elder and CO, 1857.

DARWIN, Charles. An appreciation. In: BATES, Henry Walter. The Naturalist on the River Amazons: a Record of the Adventures, Habits of Animals, Sketches of Brazilian and Indian Life, and Aspects of Nature under the Equator, during Eleven Years of Travel. London, Toronto: J. M. Dent \& Sons. New York: E. P. Dutton \& CO, 1910. p. vii-xii. Disponível em: https://bit.ly/3eylA9A. Acesso em: 28 mai. de 2020.

FERREIRA, Ricardo. Bates, Darwin, Wallace e a teoria da evolução. Brasília: Editora Universidade de Brasília; São Paulo: Editora da Universidade de São Paulo, 1990.

FOUCAULT, Michel. O que é um autor? Trad. António Fernando Cascais e Eduardo Cordeiro. 7. ed. Lisboa: Nova Vega, 2009.

ISHII, Raquel Alves. William Chandless: arte e ofício em literatura de viagem pelas Amazônias. Rio Branco: Nepan, 2019.

PRATT, Mary Louise. Os Olhos do Império: relatos de viagem e transculturação. Trad. Jézio Hernani Bonfim Gutierre. São Paulo: EDUSC, 1999.

SCHWARCZ, Lilia Katri Moritz. O espetáculo das raças: cientistas, instituições e questão racial no Brasil. São Paulo: Companhia das Letras, 1993.

THOMAS, Keith. O homem e o mundo natural: mudança de atitude em relação às plantas e os animais (1500-1800). Trad. João Roberto Martins Filho. São Paulo: Cia das Letras, 1988. WALLACE, Alfred Russel. A narrative of travels on the Amazon and Rio Negro: with an account of the native tribes, and observations of the climate, geology, and natural history of the Amazon Valley. London; New York; Melbourne: Ward, Lock \& CO,1889. Disponível em: https://bit.ly/2U0pLD0. Acesso em: 28 mai. de 2020.

Recebido em 02/06/2020. 16/08/2020. 